\title{
Grapheme-Phoneme Association Skill in High And Low Academic Achievers
}

\author{
Preeti Singh ${ }^{1}$, Akanksha Kumari ${ }^{2}$, Dr. A.K.Sinha ${ }^{3}$, Nachiketa Rout ${ }^{4}$ \\ ${ }^{I}$ (Audiologist And Speech Language Pathologist, Vishakhapattanam, India) \\ ${ }^{2}$ (Post Graduate Trainee In Speech And Hearing, AYJNIHH, ERC, Kolkata, India) \\ ${ }^{3}$ (Director, AYJNIHH, Mumbai, India) \\ ${ }^{4}$ (Associate Professor, NIPMED, Chennai, India)
}

\begin{abstract}
Reading and writing are the most basic, most central and the most essential part of learning (Bryant \& Bradley, 1983). The National Institute of Child Health \& Human development (NICHD) considers reading failure to reflect a national public health problem (Lyon, 2013). Grapheme Phoneme Association (GPA) skill (phonics) is one of the early precursors of reading disability (Justice \& Kaderavek, 2004) and is poorer in reading disabled children (Nicholson, 1992). The aim of the present study was to explore the capability of Grapheme Phoneme Association of High Academic Achievers (HAA) - children who scored more than 75 percentile marks and Low Academic Achievers (LAA) - children who scored below 35 percentile marks. The GPA checklist was made which consisted of 21 known phonemes and graphemes divided into three sets (Set I, II and III), each set consisting of seven graphemes. Each grapheme was randomly associated with an arbitrary phoneme. A significant difference between the mean scores of HAA and LAA was found in the GPA task. The Grapheme-Phoneme association checklist can be used to identify reading disability as early as possible and will be helpful for early intervention in reading disability.
\end{abstract}

Keywords: Learning Disability, Grapheme-Phoneme Association, HAA, LAA

\section{Introduction}

The term "reading disability" refers to problems associated with reading, whether it is with the mechanical skill of the reading process and/or the comprehension of what is read (Oberholzer, 2005). A reading disability in the form of deficits in phonological awareness is the most prevalent type of learning disability and affects approximately $17 \%$ of school-age children to some degree (Lyon, 1996). It is the most common learning disability in children, affecting 10-15\% of school-age children (Vellutino, Fletcher, Snowling \& Scanlon, 2004). In India around $13-14 \%$ of all school children are dyslexic (Sakhuja, 2004).

The cornerstone of academic achievement and the foundation for success across the curriculum is learning to read and write proficiently (Wilson \& Trainin, 2007). Of the 10 to $15 \%$ of children who will eventually drop out of school, more than $75 \%$ of the group will report difficulties learning to read. Failure to learn to read, places children's futures and lives at risk for highly deleterious outcomes. For this reason the National Institute of Child Health and Human Development (NICHD) considers reading failure to reflect a national public health problem (Lyon, 2003).

India is thought to have approximately ninety million people with varying degrees of learning disabilities and an average class in schools has about five students with learning disabilities (Thomas, Bhanutej \& John, 2003). Even though there is some research done in the field, (Ramma, 2000) at school levels, learning disabilities still go undetected because of the lack of adequate tests and lack of teacher training.

It is important to identify early predictors of reading success for early detection of learning disabilities at school levels. A learning disability is considered a language based difficulty (Karanth, 2003a). Reading and writing skills are dependent on various metalinguistic skills, (Paul, 1995) of which, phonics has been considered to be significant in fluency of the reading and writing skills (Catts, 1993). Phonics is a method of teaching children to read by the practice of associating particular letters or sequence of letters with particular sounds (Task, 1997). Chall (1967) states, "By learning phonics, students make faster progress in acquiring literary skills-reading and writing". Children begin learning to read using phonics usually around the age of 5 years. By the age of six, most children already have about 6,000 words in their listening and speaking vocabularies. With phonics they learn to read and write these and more words at a faster rate than they would without phonics (Wikipedia, 2011)

The speech pathologists, thus, have a crucial role to play in preventing reading disabilities, even before a child presents typical reading and writing errors (American Speech-Language- Hearing Association, 2001; Kaderavek \& Justice, 2004).

Low academic achievement has been defined as failing to meet the average academic performance in tests or examination scores, as determined by a set cut-off point (Fletcher, Coulter, Reschly, \&Vaughn, 2004; 
Fletcher, Shaywitz, Shankeeiler, Katz, Liberman, Stuebing et.al., 1994). The Central Board of Secondary Education (CBSE) (2004) gave "The Guidelines on Continuous and Comprehensive Evaluation at Primary Level" where the student's achievement in different areas, were reported through indirect grading on an absolute scale containing five points. The grades stand for the different distribution of marks as shown in Table 1.

Table-1: - Representing the Reporting Student's Achievement (The Central Board of

Secondary Education, 2004)

\begin{tabular}{|c|c|c|}
\hline A $^{*}$ & Outstanding & $90 \%-100 \%$ \\
\hline A & Excellent & $75 \%-89 \%$ \\
\hline B & Very Good & $56 \%-74 \%$ \\
\hline C & Good & $35 \%-55 \%$ \\
\hline D & Scope for improvement & Below 35\% \\
\hline
\end{tabular}

The criteria includes, children who scored more than 75 percentile marks (grade $\mathrm{A}$ and $\mathrm{A}^{*}$ ) were considered high achievers and those with below 35 percentile marks (Grade D) were considered low achievers, based upon the performance in their last final examination.

The Grapheme-Phoneme Association skill (phonics) is one of the early precursors of a reading disability (Justice \& Kaderavek, 2004) and is poorer in reading disabled children (Nicholson, 1992; Stanovich, 1986). Poor academic achievers are at risk of developing a reading disability (Mathes \& Denton, 2002; Kirby, 2003). As phonics develops very early in childhood, a poor Grapheme-Phoneme Association skill is identified early and intervened early, which may reduce the incidence of developing a reading disability. The present study attempts to explore the difference in Grapheme-Phoneme Association skill (phonics) between high and low academic achievers attending CBSE affiliated schools in Kolkata city.

\section{Method}

Participants:

A total of 80 participants aged 8-10 years were categorized equally into two groups:-, Group A (17 male and 23 females) comprised of high academic achievers (HAA), Group B (18 male and 22 females) comprised of low academic achievers (LAA). The participants were placed into Group A and Group B by using Central Board of Secondary Education (CBSE) 2004 criteria. All the participants were drawn from Standard III or Standard IV of a regular CBSE, English, medium school, located in Kolkata. All the participants were aware of both Hindi Varnamala and the English alphabets since their kindergarten ages. All the participants came from middle socioeconomic strata and were ruled out for any sensory impairment.

\section{Tools:}

\section{Grapheme-Phoneme Association checklist (GPA checklist) - Checklist construction:-}

A Grapheme-Phoneme Association checklist (GPA checklist) was developed by using known graphemes and known phonemes to reduce the demand on auditory and visual memory of the child. Twenty-one graphemes and phonemes were selected randomly from the English alphabets and Hindi Varnamala respectively. The selected graphemes and phonemes were given to teachers of Standard III \& IV to ensure that students of Standard III \& IV are aware of these graphemes and phonemes. Twenty-one graphemes and phonemes were grouped in 3 sets (Set I, Set II and Set III) randomly. Each grapheme was randomly associated with an arbitrary phoneme. Each set consisted of seven graphemes and associated phonemes. Individual graphemes of each set of the GPA checklist were printed in the middle of each $11.5 \times 7.5 \mathrm{~cm}$ flash card. Thus, there were three sets of 21 flash cards (Set A, Set B and Set C) containing 21 graphemes.

\section{Procedure}

A detailed case history was taken for each participant prior to the administration of the test. The participants were screened to rule out the presence of any sensory or emotional problems by interviewing parents and teachers. Visual-perception errors were ruled out by asking the participants to identify English alphabets graphemes.

Administration of GPA checklist: - The GPA checklist was administered in a quiet-environment and in a one to one setting with adequate lighting. English alphabets were shown to the child and they were asked to identify the target letters. The test was continued for only those participants who identified and read the target graphemes/letters.

At first, Set I of the GPA checklist was administered. One grapheme printed on each flash card was shown to each participant individually. The sequence of the presentation of cards was different for each successive participant. Before administration of the test, the following instruction was given: 
"Now, we are going to play a game. I will show you some letters and will give them some names. For example: - Look at the letter 'A': We will call this /S/. Similarly, I will show you seven letters and allot some names to them. You must pay attention because I am going to ask you their names later”.

In order to make sure that the participants understood the instruction, instructions were repeated, but not more than five times. After a gap of one minute, one set of cards was presented to each individual participant containing the particular graphemes in a random order, preceded by the following instruction:

"Now, I will present seven cards containing letters and you have to tell the name of the presented letter that I had told you earlier as quickly as possible."

Each card was presented for three seconds and if the child did not respond, the next card was presented. Similar tests were completed for Set II and Set III of the GPA checklist with a gap of five minutes after each set.

Responses were marked "correct" or "incorrect" by the examiner while simultaneously testing. A score of ' 0 ' was given for an incorrect response and ' 1 ' for a correct response. Those participants who responded incorrectly for the first three consecutive cards were discontinued for further testing. Scores obtained for Set I, II and III of the GPA checklist were added to get the final score of the participant. The total time duration for administering the checklist for one participant was around thirty minutes.

The score obtained by the participants were tabulated numerically. Each set had a total score of seven and thus, the maximum score obtained by combining the total score of each set was twenty-one. The scores were also grouped into four sub-groups: Group I consisted of scores 0-5, Group II consisted of scores 6-10, Group III consisted of scores 11-15 and Group IV consisted of scores 16-21.

In order to compare the overall performance of Group A (HAA) and Group B (LAA) on the developed GPA checklist, descriptive statistics, a chi square test and an independent t-test were done-by using SPSS Version 16 and a test for equality of binomial proportion was completed by using a formula and the results are reported below.

\section{Results And Discussion}

A descriptive analysis of the scores obtained by Group A (HAA) and Group B (LAA) using the GPA checklist was done. The mean score obtained by Group A (HAA) was 16.8 (SD =2.45145) and by Group B (LAA) was $7.2(\mathrm{SD}=1.84651)$.

The mean value and, the maximum and minimum value of scores obtained by Group A (HAA) and Group B (LAA) are shown graphically by using box plots in Figure II. -The maximum value of Group A was 21 and of Group B were 11, while the minimum value of Group A was 12 and of Group B was 4.

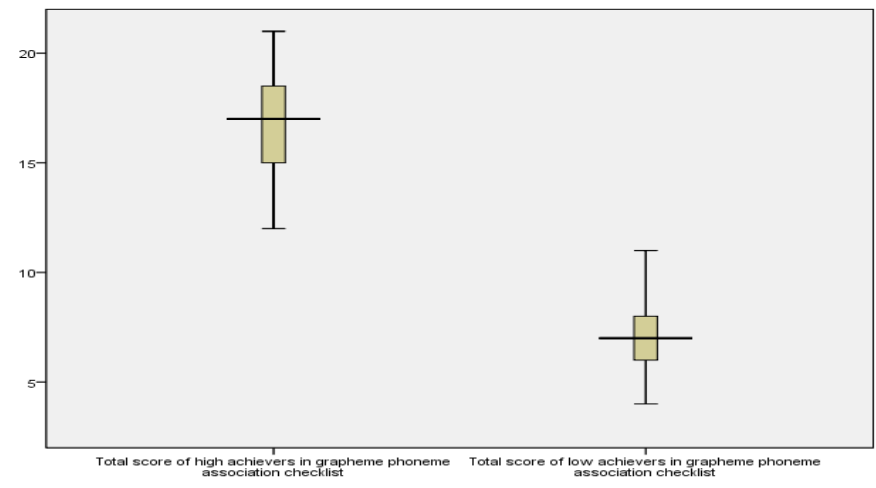

Figure II: - Box Plots

Poor performance of poor achievers on the Grapheme-Phoneme Association task may be due to the poor short-term memory of poor achievers. Short-term memory is the memory for immediate recall. Learning phonics requires both intact memory as well as visuo-spatial skills (Roy, Paul \& Goswami, 2010). It has been found that children with a reading disability show deficits in both visual and auditory short-term memory (Roy, Paul \& Goswami, 2010). Strong evidence indicates the effect of short-term memory on remembering the diction datum is shown in children with a reading disability who usually show high deficits, and thus, most poor readers have weak phonic skills (Blevins, 1998).

A Pearson chi square test of independence was done to test the relationship between the scoring pattern (represented by four sub-groups I, II, III and IV) and the two Groups: A (HAA) and B (LAA). The chi square 
value of 73.143 with d.f. $=3$ was obtained, with the p-value nearly $0(p<0.05)$. The difference in the scoring pattern of Group A (HAA) and Group B (LAA) has been represented graphically in Figure III.

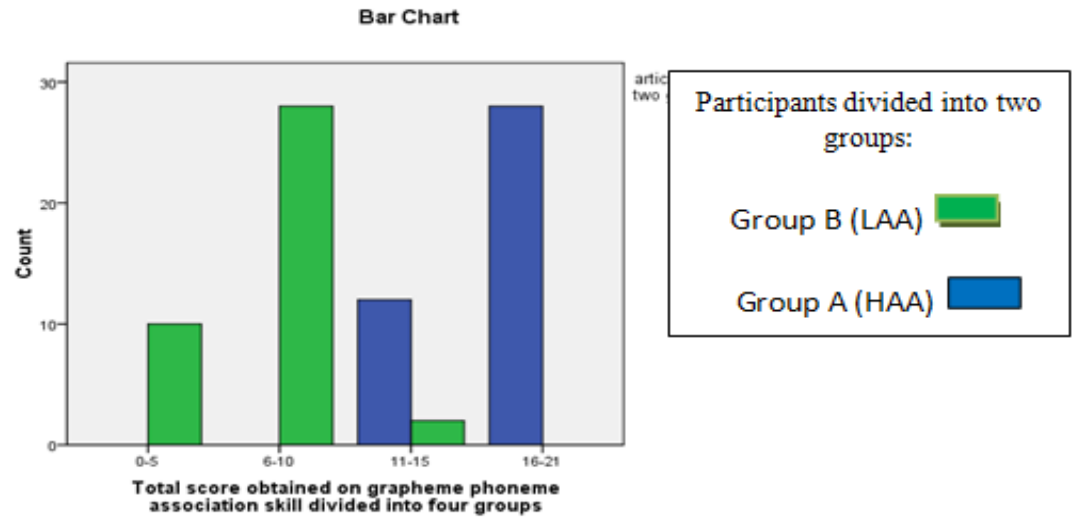

Figure III:- Relationship between scoring pattern and Group A (HAA) and Group B (LAA)

Phonics knowledge positively affects decoding ability (Stanovich \& West, 1989). Early attainment of decoding is important because it accurately predicts later reading comprehension skills (Beck \& Juel, 1995). Thus, poor academic achievers who have poor phonics skills have a weak decoding ability, which affects reading.

Poor readers have consistently been found to perform below the level of normal readers on phonological awareness tasks (Hulme, Snowling, Caravolas, \& Carroll, 2005). Difficulties in acquiring phonological awareness and skills in alphabetic coding are believed to be weak in many cases due to phonological coding characterized by poor quality of the underlying sub- lexical phonological representations (Griffiths \& Snowling, 2002). Shaywitz (1996) has argued that dyslexia may represent the low end of a reading disabilities continuum rather than a separate disability, as they both stem from a language system disorder, namely, the phonological system. Others have demonstrated that reading weaknesses can develop into dyslexia or a reading disability when neglect is a factor (Mathes \& Denton, 2002; Kirby, 2003).

Individuals who experience early decoding difficulties tend to read less, and thereby, grow less in terms of word-recognition skills and vocabulary. A longitudinal study conducted by Juel (1988), revealed an 88\% probability that a child who is a poor reader at the end of first grade would still be a poor reader at the end of fourth grade. Stanovich (1986) refers to this as the "Matthew Effect" in which the "rich get richer" (children who are successful decoders read more, and therefore, improve in reading), while the "poor get poorer" (children who have difficulties decoding become increasingly distanced in reading ability from the strong decoders). Therefore, poor readers who have poor phonics skills faces difficulty in reading at early ages, and rarely catch up with their peers later, and thus, become reading-disabled.

As poor academic achievers have poor Grapheme Phoneme Association skills (phonics), and poor achievers are at risk of developing reading disability, by assessing phonics, reading disabilities may be predicted.

Levene's Test for Equality of Variances was significant. The mean of Group A (HAA) was 16.8 (SD $=2.45145)$ and that of Group B (LAA) was $7.2(\mathrm{SD}=1.84651)$. The mean difference obtained was 9.65, with $\mathrm{t}-$ value 19.886, and d.f. $=78$, with the interval of difference 0 . The result of the independent test is shown in Table 5.

Table 5:- Comparison of Scores of Group A (HAA) and Group B (LAA) on Grapheme-Phoneme Association Skills

\begin{tabular}{|c|c|c|c|c|c|c|c|c|c|c|}
\hline \multicolumn{11}{|c|}{ Independent Samples Test } \\
\hline & & \multicolumn{2}{|c|}{$\begin{array}{l}\text { Levene's Test } \\
\text { for Equality } \\
\text { of Variances }\end{array}$} & \multicolumn{7}{|c|}{ t-test for Equality of Means } \\
\hline & & \multirow[t]{2}{*}{$\mathrm{F}$} & \multirow[t]{2}{*}{ Sig. } & \multirow[t]{2}{*}{$\mathrm{T}$} & \multirow[t]{2}{*}{ d.f. } & \multirow[t]{2}{*}{$\begin{array}{l}\text { Sig. (2- } \\
\text { tailed) }\end{array}$} & \multirow[t]{2}{*}{$\begin{array}{l}\text { Mean } \\
\text { Difference }\end{array}$} & \multirow[t]{2}{*}{$\begin{array}{l}\text { Std. Error } \\
\text { Difference }\end{array}$} & \multicolumn{2}{|c|}{$\begin{array}{l}95 \% \text { Confidence Interval } \\
\text { of the Difference }\end{array}$} \\
\hline & & & & & & & & & Lower & Upper \\
\hline $\begin{array}{l}\text { Total } \\
\text { score } \\
\text { obtain } \\
\text { ed on } \\
\text { graph }\end{array}$ & $\begin{array}{l}\text { Equa } \\
1 \\
\text { varia } \\
\text { nces } \\
\text { assu }\end{array}$ & 3.134 & .081 & 19.886 & 78 & .000 & 9.65000 & .48526 & 8.68391 & 10.61609 \\
\hline
\end{tabular}




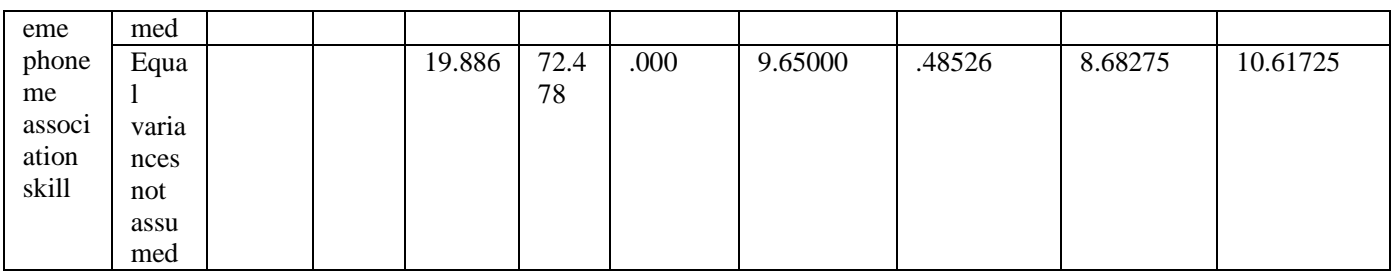

Since the normality of distribution of scores in Group A (HAA) and Group B (LAA) was unknown, a test for Equality of Binomial Proportion was done. A test statistics T-test was calculated, on the basis of the proportion of correct scores of Group A (HAA) and Group B (LAA).

Table 6:- Proportions of Correct Scores in Groups A (HAA) and B (LAA)

\begin{tabular}{|l|l|}
\hline Proportions of correct scores in Group A & 0.8 \\
\hline Proportions of correct scores in Group B & 0.34 \\
\hline
\end{tabular}

Poor phonics skills in poor academic achievers have been linked with language. There has been support for the ideas that early language development is related to later reading skills (Grizzle, 2005). Children whose language difficulties had been resolved by 5 years of age had developed good reading and spelling skills in contrast to the group that had a persistent communication disability (Bishop \& Adams, 1990). Children who have strong skills at the phonologic level of language are in a better position to recognize that the words they hear can be broken into individual sounds and, in turn, will be cognitively ready to perform the most basic of reading skills:- decoding words (i.e., phonetically sound out words). Decoding forms the basis for reading development (Grizzel, 2005). Poor academic achievers in schools usually under perform in spelling, literature and oral examination, -which may be attributed to their poor metaphonological skills (Exposito, 2007). Metaphonology is an aspect of metalinguistics (Karanth, 2003a). Metalinguistic skills help the child to read printed form, which is related to their school performance. Many unsuccessful readers have been shown to lack letter knowledge, phonological awareness, grapheme-phoneme skills and oral language (Snowling et al., 2003). Thus poor achievers with deficits in metalinguistic skills (Karanth, 2003a) have poor phonics skills as compared to good readers.

\section{Summary And Conclusion}

The GPA checklist can be used as a tool for assessment of Grapheme-Phoneme Association in children in the age range of 5-8 years. Children with low academic achievement in schools may be intervened for developing Grapheme-Phoneme Association to develop literacy skills at an early stage.

The Assessment of Grapheme -Phoneme Association through the GPA checklist may help to identify children with a reading disability and guide speech-language pathologists to plan early intervention.

\section{References}

[1]. American Speech- Language- Hearing Association. (2001). Roles and Responsibilities of SpeechLanguage pathologist With respect to Reading and Writing in Children and Adolescents [Guideline]. Retrieved on December 12 from http://www.asha.org/policy.

[2]. Beck, I., \& Juel, C. (1995). The role of decoding in learning to read. AmericanEducator, 8, 21-25, 39-42.

[3]. Bishop DVM, Adams C. (1990). A prospective study of the relationship between specific language impairment, phonological disorders and reading retardation. Journal of Child Psychology and Psychiatry and Allied Disciplines, 31(7):1027-1050.

[4]. Blevins, W. (1998). Phonics from A to Z A Practical Guide. Scholastic Inc,555 Broday, NewYork.

[5]. Catts, H. W. (1993). The relationship between speech-language impairments and reading disabilities. Journal of Speech \& Hearing Research, 36, 948-958.

[6]. Chall, J. S. (1967), Learning to Read: The Great Debate. McGraw-Hill New York.

[7]. Continuous and Comprehensive Evaluation, CENTRAL BOARD OF SECONDARY EDUCATION (2004), Retrieved on 19 December, 2011, from cbse.nic.in./CCE\%20Certificate-2009-11-A3\%20size\%20.

[8]. Exposito, S.H. (2007). Locus and Nature of Perceptual Phonological Deficits in Spanish Children with Reading Disabilities. Journal of Learning Disabilities, 40 (1), 80-92.

[9]. Fletcher, J.M., Coulter, W.A., Reschly, D.J., \& Vaughn, S. (2004). Alternative Approaches to the Definition and Identification of Learning Disabilities: Some Questions and Answers. Annals of Dyslexia, 54(2), 304-332.

[10]. Griffiths, Y. M., \& Snowling, M.J. (2002). Predictors of exception word and non word reading in dyslexic children: The severity hypothesis. Journal of Educational Psychology, 94, 34-43.

[11]. Grizzle K. L., Simms. M. D. (2005). Early language Development and Language learning Development Disabilities. Pediatrics in Review.26,8.

[12]. Hulme, C., Snowling, M., Caravolas, M., \& Carroll, J. (2005). Phonological skills are (probably) one cause of success in learning to read: A comment on Castles \&Coltheart. Scientific Studies of Reading, 9, 351-365.

[13]. Justice, L.M., \& Kaderavek, J.N. (2004). An embedded-explicit model of emergent literacy intervention for young at-risk children: Part I. Language, Speech, and Hearing Services in Schools, 35, 201-211.

[14]. Karanth, P. (2003a). Language and Learning Disability or Language Learning Disability. In: P. Karanth (Ed.). Learning Disabilities in India Willing The Mind to Learn. 127-137, New Delhi: Saga Publications.

[15]. Kirby, J.B., (2003). The development of reading disabilities. Paper presented at theAQETA/LDAQ March conference in Montreal. 
[16]. Lyon G. R. (1996). The Future of Children: Special education for students with disabilities, Learning Disabilities Vol. 6 • No. 1 Spring .

[17]. Lyon, G. R. (2003). Reading Disabilities: Why Do Some Children Have Difficulty Learning to Read? What Can Be Done About It? The International Dyslexia Association's Quarterly Periodical, Perspectives, 29, 2, 17-19.

[18]. Mathes, P.G. \& Denton, C.A. (2002). The prevention and identification of reading disability. In I.J. Butler (Ed.), Language development and disorders in childhood. J.B. Bodensteiner (Ed.), Seminars in pediatric neurology.

[19]. Nicholson, (1992). In Blevins, W. (2003). Phonics and the beginning reader. Scholastic Inc, 555 Broday NewYork.

[20]. Oberholzer. B (2005). The relationship between reading difficulties and academic performance among a group of foundation phase learners who haye been: identified as experiencing difficulty with reading and) referred for reading remediation. A unpublished dissertation submitted in Department of Educational Psychology, University of Zululand.

[21]. Paul, R. (Eds.). (1995). Language disorders from infancy through adolesence. New York: Mosby.

[22]. Ramaa(2000). In Chapter Three Specific Learning Difficulties Action Research from www.actionresearch.net/living/rawalpdf/Chapter3.pdf.

[23]. Roy, M. E., Paul, S., \& Goswami, S. P. (2010), Verbal Memory Span and Sequential Memory in Children with Learning Disability. Journal of Indian Speech and Hearing Association, 23, 19-24.

[24]. Sakhuja, S. (2004). Education for All and Learning Disabilities in India. (Article No 9).Retrived December, 2011, from http://sspconline.org/article_details.asp?artid=art 10 .

[25]. Shaywitz SE. Dyslexia (1996). Scientific American.;275:98 -104.

[26]. Stanovich, K. E. (1986). Matthew effects in reading: Some consequences of individual differences in the acquisition of literacy. Reading Research Quarterly, 21, 360-407.

[27]. Stanovich, K. E., \& West, R. F. (1989). Exposure to print and ortho-graphic processing. Reading Research Quarterly, $24,402-433$.

[28]. Thomas, Bhanutej \& John, (2003). In Chapter Three Specific Learning Difficulties Action Research from www.actionresearch.net/living/rawalpdf/Chapter3.

[29]. Vellutino, F. R., Fletcher, J. M., Snowling, M. J., \& Scanlon, D. M. (2004). Specific reading disability (dyslexia): What have we learned in the past four decades? Journal of ChildPsychology and Psychiatry, 45, 2- 40.

[30]. Wilson and Trainin, (2007). In What teachers need to know about Reading and writing difficulties, 2008 by ACER Press, an imprint of Australian Council for Educational Research Ltd.

[31]. Wikipedia, (2011). Phonics retrieved on $4^{\text {th }}$ December, 2011 from fttp:///Phonics\%20\%20Wikipedia,\%20the\%20free\%20encyclopedia. 